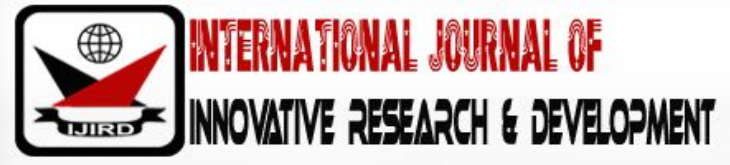

ISSN 2278 - 0211 (Online)

\section{The Use of Modal Auxiliary Verbs in Composition Writing among Standard Six Pupils of Diverse Language Backgrounds in Nakuru County, Kenya}

\author{
Jane Ngoirinjuguna \\ Teacher, Department of English, St. Lwanga Primary School, Nakuru County, Kenya
}

\begin{abstract}
:
The study focused on the use of English modal auxiliary verbs by class six pupils from diverse language backgrounds in Kenyan primary schools. Modal auxiliary verbs are difficult as their use entails syntactic and semantic appropriateness. As such, most pupils often find themselves unable to use this complex linguistic feature in written English. In spite of this, there is no known documentation that focuses on modal auxiliary verbs among children. It is this gap that the current study sought to fill. The rationale of the study was therefore to describe the use of this linguistic feature at this foundation level of learning so that appropriate measures can be taken by the stakeholders so as to alleviate further difficulties that students might encounter in their progressive learning of English. The main objective of the study was thus to describe appropriateness of modal auxiliary verbs in class six written English. Forty pupils were randomly selected from four primary schools in Nakuru County. Data was elicited by means of written composition and grammar exercises. Further, it was analyzed both quantitatively and qualitatively and presented in form of graphs and tables. The Representational Theory of the Mind was used to explain the research findings. The findings revealed that modal auxiliary verbs are indeed difficult and their appropriate use present difficulties in pupils' written work.
\end{abstract}

Keywords: Modal auxiliary, composition, diverse, language, background

\section{Introduction}

\subsection{Background of the Study}

English is an official language in Kenya. In fact, the Kenyan constitution (2010) recognizes English and Kiswahili as the official languages. It is accessible to most communities and deemed prestigious by elites. It is also well established in primary school system where it is a medium of instruction and used in teaching all subjects except Kiswahili. English is also an examinable subject at Kenya Certificate of Primary Education (KCPE).

Subsequently, at the end of primary education, pupils are expected to have acquired sufficient command of English in both spoken and written modes to enable them communicate efficiently and logically. Unfortunately, this is not always the case. In our Kenyan context, English is learnt as a second language. The learning of English takes place formally in the classroom while acquisition takes place outside the classroom. The learning process brings into perspective some fundamental elements: the pupil, the teacher, the strategies employed and the resource materials used. The interplay of these elements is bound to pose challenges in the learning of English and in particular the learning of the modal auxiliary verbs.

A class six learner of English is normally aged between 12-15 years. Majority of these pupils are bilinguals since they come from diverse language backgrounds. Class six pupils are generally proficient in at least three languages but interestingly, some can speak up to five languages especially those in Nakuru County which is highly cosmopolitan.

A pupil's affiliation to their first language could impede their learning and acquisition of modal auxiliary verbs in English. This is because the verb system in different languages is unique. Some of the pupils' first languages have modal auxiliary verbs similar or different from those of the English language. At this level, pupils will also have learnt or acquired Kiswahili which also affects their modal auxiliary usage.

Class six pupils do not only come from diverse language backgrounds but also from different social classes. The social classes they belong to affect their socialization process. If a pupil has been socialized in a manner that s/ he perceives English as prestigious he/ she is likely to perform better than those who have been socialized differently. 
Besides, the affiliation to an ethnic community, a class six pupil is a member of a social group and is often compelled to identify with his or her peer group. The dominant language usage which characterizes these learners is sheng, code-switching and code mixing. These language characteristics may have adverse effects on the learning of modal auxiliary verbs. This is because these language behaviors limit pupils' opportunities to express themselves in English thereby impoverishing their English language mastery.

The language policy in education in Kenya is very clear about the place of English in schools. Unfortunately, it is silent about the use of English language in the school compound yet studies about the link between English language use and proficiency in English have established that English language use does indeed enhance English language learning outcome.

The language policy in education clearly stipulates that English be used as a medium of instruction. Interestingly, this is hardly the case as code-switching, code-mixing and even in extreme cases, mother tongue are used as a medium of instruction in teaching of English even at class six. These circumstances pose severe challenges in the learning and use of English modal verbs.

Furthermore, the language policy in education states that mother tongue should be used as a medium of instruction in lower primary or Kiswahili in urban and municipality schools and English be used in upper primary. Ideally, class six pupils are in the sixth year of learning English as a subject and at their third year in using English as a medium of instruction. Despite this stipulation, class six pupils still grapple with English language use especially those in public primary schools so much that using English as a medium of instruction becomes challenging.

English modal auxiliary verbs are syntactic and semantic elements of the complex English verb phrase. Modal auxiliary verbs indicate modality. Modality in this sense implies permission, ability and obligation. Modal verbs have both grammatical and semantic properties. For this reason the use of modal verbs presents unique difficulties for class six learners.

At class six, a pupil will have been exposed to a variety of modal verbs in the previous years. At class one may for permission is taught can and shall in class two while will, shall and could are taught in class three as for may, can, could and would they are taught in class six. The remaining central modal verbs; must and should are taught in class seven and eight. The English language syllabus only identifies the modal verbs to be taught at this level but does not actually specify the scope of modal verbs that should be taught.

\subsection{Statement of the Problem}

Although various child language based studies have been conducted, to the best of the researcher's knowledge there is no known documentation on the use of English modal auxiliaries in written English among children from diverse language backgrounds. Modal auxiliaries usage presents inherent difficulties even among first language speakers of English. For second language learners of English, more so those in primary schools, modal verbs are bound to pose even greater challenges since they entail syntactic and semantic appropriateness.

Appropriateness of modal auxiliary use is crucial for communication. Available literature reveals that modal auxiliary verbs are difficult even among advanced learners of English. Pupils in Kenya are drawn from different socio-economic classes and the learning of English takes place in environments with immense disparities yet all pupils are subjected to the same rigorous English national examination. A study on modal auxiliary use among this cadre of learners is essential as learning of English in primary schools lays a foundation in which later learning is laid.

\subsection{Objective}

To describe the use of English modal auxiliaries in class six written English.

\subsection{Scope}

The study investigated modal auxiliary use in class six written English. Its main focus was the use of the nine central English modal verbs which are; can, may, could, might, will, may, must, would and shall. The study investigated how pupils used the same modal verb in different contexts to convey the same or varied meaning.

\section{Methodology}

\subsection{Research Design}

Since the purpose of this study was to describe modal verb use in class six written English, a descriptive research design was deemed appropriate. In this study, occurrences and appropriateness of modal auxiliary use were described. Description of use of English modal auxiliary verbs was limited to written English. The data collected was quantitatively and qualitatively described.

\subsection{Study Location}

The study was conducted in Nakuru County. This county has nine districts with both rural and urban population. Two districts were selected for the purpose of this study; Nakuru Town and Nakuru North. Nakuru town was purposively selected because of its highly cosmopolitan nature; an aspect the study hoped to capture and relate it to frequency and appropriateness 
of modal auxiliary use. As for Nakuru North district it was selected because of its rural and ethnic diversity. . There are well over fifteen languages being spoken here in both rural and urban parts of Nakuru.

\subsection{Target Population}

The study targeted both rural and urban population of class six learners of English from various language backgrounds. Schools that were deemed to meet the above criteria were selected. A total of four schools were randomly selected. Schools A and B were selected from urban and sub-urban areas of Nakuru County respectively. Schools C and D were selected from the rural areas of Nakuru County.

\subsection{Sampling Technique and Sample Size}

In this study, both purposive sampling and random selection techniques were employed. Once Nakuru town was purposively identified, ten urban high cost schools within Nakuru municipality were identified. Random selection was conducted so as to arrive at School B. Six public primary schools from the sub-urban areas of Nakuru County were also identified from which School A was randomly selected. Purposive sampling technique was employed so as to capture the rural population. In this way Nakuru North district was captured. There was need to compare a school with one dominant language group so as to compare the findings of the study with those of the schools with pupils of diversified language communities thus School C was randomly selected. Also, considered was the need to capture a rural school with a less ethnic composition. To capture such a school a random selection was conducted so as to arrive at School D.

\subsection{Data Collection Procedures}

Test one was administered by the researcher herself and the schools were paid two visits on two consecutive days. The four schools were far apart. The distance between the schools ensured that there was no leakage of the tests. The test was administered to those pupils in the urban and sub-urban schools (Schools A and B) and then to the school in the rural areas (Schools C and D). Pupils were given ample time to write the compositions and were not restricted to the normal forty minutes.

\subsection{Research Instrument}

Pupils were given a spontaneous composition writing Test on either the topic My Favorite Pet or My Favorite Game. This composition was to between 200 and 250 words. The topics selected were deemed appropriate because of their potential to elicit various modal auxiliary verbs such as we should take care of our pets or I can play football. Furthermore, the topics given were within the cognitive and linguistic level of the learners.

\subsection{Data Analysis Procedures}

Data analysis involved three main procedures; the cleaning, correcting and coding of the data. Compositions were read and all the modal verbs used in individual compositions were identified after which they were entered in the segmentation column. There was also column segmentation for use per school.

\section{Findings}

\subsection{Frequency of Modal Auxiliary Verbs in Test One}

The Test consisted of two compositions; My Favorite Pet and My Favorite Game. Pupils were asked to choose either of the compositions. A total of forty compositions were written. Twenty six pupils wrote Composition One (My Favorite Pet) and fourteen pupils wrote Composition Two (My Favorite Game). The graph below summarizes the choice of compositions made by pupils.

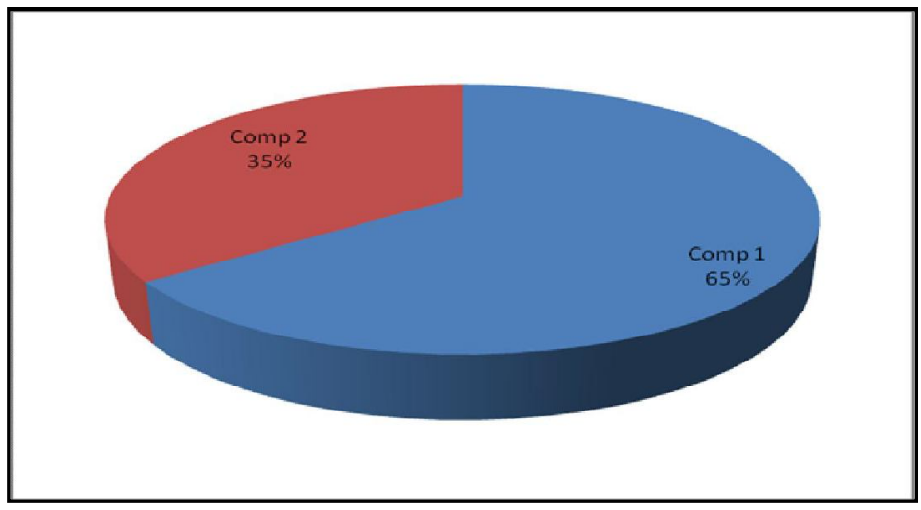

Figure 1: Choice of Composition Made by Pupils 
The graph indicates that majority of the pupils opted for Composition One. In fact, all the pupils from School B wrote this composition. Since these compositions were spontaneously written the pupils' choice could indicate that they were more familiar with the topic given in Composition One than in Composition Two. At class six pupils are more familiar with adventure and animal stories than in games.

\subsection{Frequency of Modal Auxiliary Use in Composition One (My Favorite Pet)}

Composition one elicited all the modal verbs whose occurrences were examined except for the modal verb may. The figure given below illustrates this:

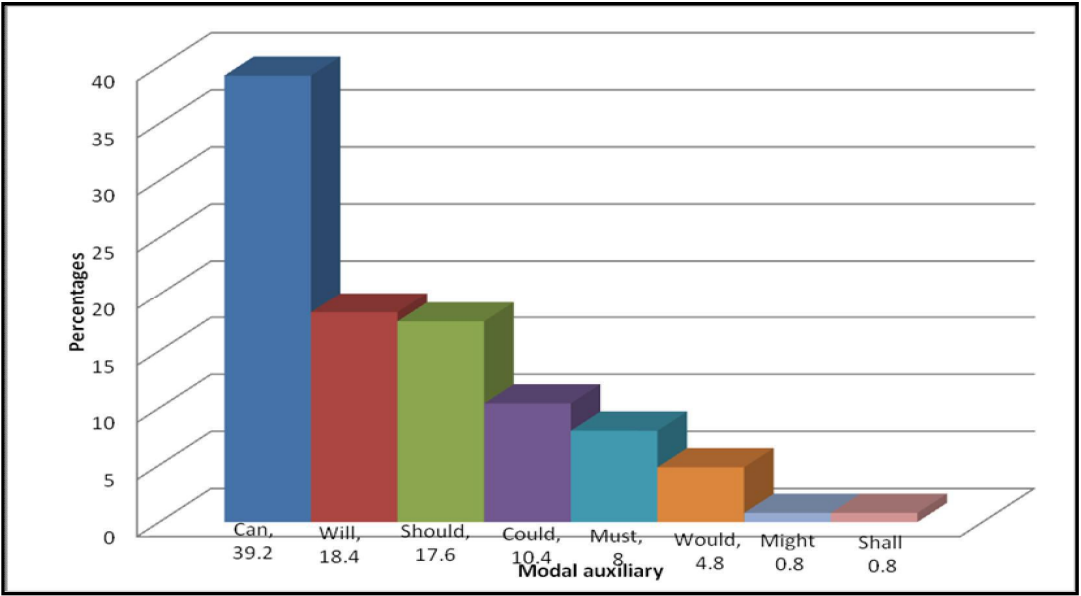

Figure 2: Frequency of Modal Auxiliary Verbs in Composition One

The figure shows that modal auxiliary verbs use differed. Can was the most appropriately used modal with $39.2 \%$ of use, while shall and might were the least used modal verbs with $0.8 \%$ frequency of use. This means the choice of modal verb is determined by the topic given. It is important to note that even the highest used modal (can) scored below 50\%. It therefore means that modal verbs were not very frequently used in this composition. Can and will were relatively more frequently used.

\subsection{Frequency of Modal Auxiliary Use in Composition Two (My Favorite Game)}

In this composition, seven out of the nine central modal verbs were used. Below is a presentation of frequency of use.

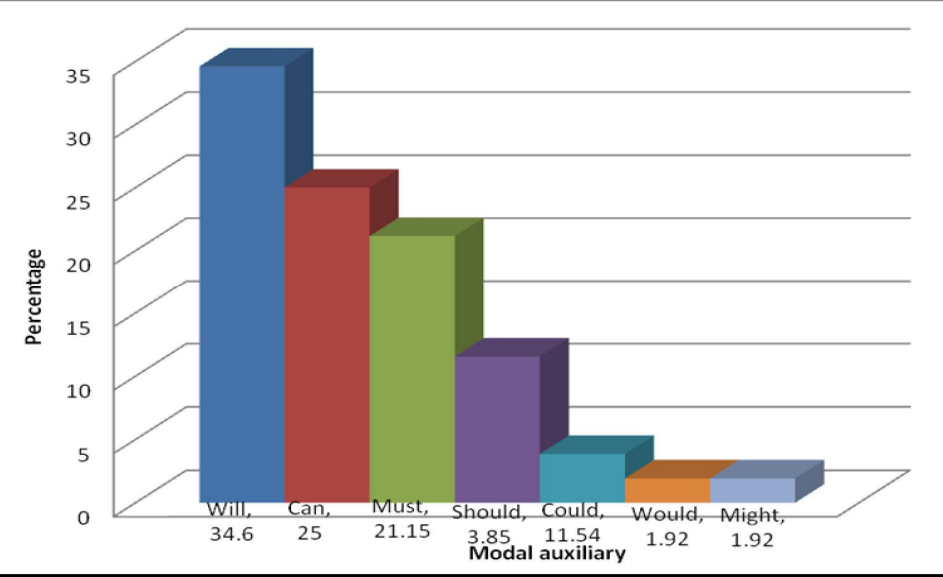

Figure 3: Frequency of Modal Auxiliary Verbs Use in Test Two

The most frequently used modal auxiliary verb in this composition was will with $34.6 \%$ followed by can with $25 \%$. The modal verbs shall and may were not used at all. It is to be noted that the modal auxiliaries can and will have the highest frequency of use in both compositions. This is perhaps due to what pupils at class six have learnt or acquired from their environment. Surprisingly, the modal verbs would and might were not very frequently used in both compositions. Probably, frequency of use is not so much determined by the topic given to pupils at this level but rather by what has been learnt or acquired. This perhaps underscores the fact that in The Representational Theory of The Mind, there is a link between one's natural and social environment and the content of mental representation. 


\subsection{Frequency of Modal Auxiliary Use in Composition One Use per School}

Frequency of modal auxiliary use differed from school to school in Composition One. This is both in terms of modals that each school yielded and the number of frequency for each modal verb. This is illustrated in the pie chart given below.

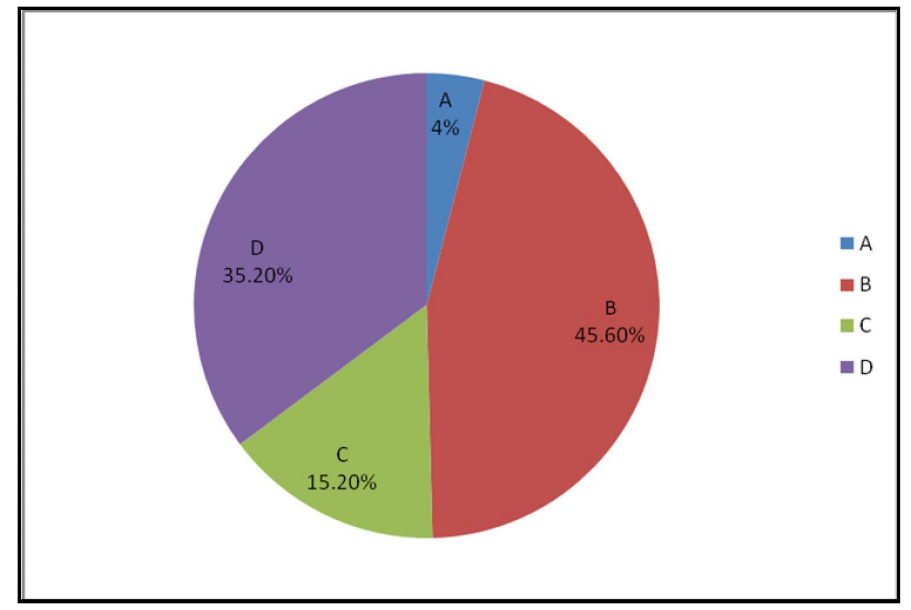

Figure 4: Frequency of Modal Auxiliary Use in Composition One Use per School

The graph shows that School B had the highest modal auxiliary verb use (45.6\%) in Composition One while School A had the least modal auxiliary use (4\%). The finding here reveals that pupils in School B are probably more exposed to modal auxiliary verb use than the Schools A,C and D. Exposure in modal auxiliary use is through learning and acquisition processes. School B, being a high cost private school implies that the learning resources are much more accessible to these pupils. Language promoting activities are more diverse in comparison to other schools. Another implication of this finding is that pupils in this school were more familiar with the topic of choice and used modal verbs with ease. In terms of distribution of modal auxiliary use, interestingly, School B used seven out of nine modals. School C used eight out of the nine modals but still School B used more modals. This probably suggests that pupils in School B were more confident in their choice of modals. As for School A they had the least distribution of modal verbose. Low distribution of modal use could imply either lack of knowledge of modals due to failure of learning or acquiring them.

School A recorded the highest frequency of modal use in Composition Two. It also had the highest modal distribution. Pupils from School A, being residents of the sub-urban area of Nakuru town were more familiar with the topic than pupils from other schools. Familiarity with the subject of choice sometimes yields more auxiliary verbs. Generally, urban schools are more conversant with sporting activities than rural schools. Can and will remained the pupils' favorite choice of modal auxiliary verb use. The data collected in both compositions showed significant trends; that some modals verbs were more frequently used than others and that pupils from different schools used modals differently.

\section{Conclusion}

Acquisition plays a significant role in modal auxiliary frequency. The use of must and shall in the data illustrates this fact. Although the modal auxiliary shall islearnt in Class Two and it is quite infrequent in use outside the classroom must islearnt in Class Seven and Eight yet it is frequent in Test Two. In the school system the use of the modal verb must is frequent as it is used when teachers are giving instructions to pupils. In the process of so doing pupils acquire its use and this explains why even though it has not been learnt its use is relatively high. This means learning and acquisition go hand in hand with language learning.

\section{References}

1. Republic of Kenya. (1999) Report of the Commission of inquiry, into the Education System of Kenya; Nairobi: Government Printer.

2. Republic of Kenya. (2002). Ministry of Education, Science and Technology, Primary Education Syllabus; Volume One; Nairobi: Kenya Institute of Education.

3. Fodor, J. (2010). LOT2: The Language of Thought Revisited. Oxford and New York: Oxford University Press

4. Mugenda, O. \& Mugenda A. (2012) Research Methods: Dictionary of Applied Research and Training Service. Nairobi: Acts press 